\title{
Towards efficient and cost-effective inverted hybrid organic solar cells using inorganic semiconductor in the active layer
}

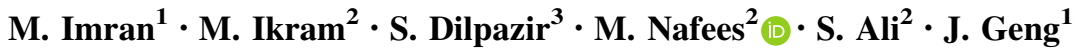

Received: 19 July 2017/ Accepted: 7 October 2017/Published online: 16 October 2017

(c) The Author(s) 2017. This article is an open access publication

\begin{abstract}
The article investigates the effects of $\mathrm{NiO}$ (ptype) and $\mathrm{TiO}_{2}$ (n-type) nanoparticles (NPs) on the performance of poly(3-hexylthiophene) (P3HT) and (phenylC61-butyric acid methylester) (PCBM) based devices with an inverse geometry. Various weight ratios of these nanoparticles were mixed in the polymer solution using 1,2-dichlorobenzene as solvent. An optimal amount of NPs-doped active layer exhibited higher power conversion efficiency (PCE) of $3.85 \%$ as compared to the reference cell, which exhibited an efficiency of $3.40 \%$ under white light illumination intensity of $100 \mathrm{~mW} / \mathrm{cm}^{2}$. Enhanced PCE originates from increased film roughness and light harvesting due to increased absorption range upon mixing an optimal amount of NPs in the organic-based active layer. Further addition of $\mathrm{NiO}$ and $\mathrm{TiO}_{2}$ concentration relative to PCBM resulted in significant agglomeration of nanoparticles leading to degraded device parameters.
\end{abstract}

M. Imran and M. Ikram are equal contributors.

M. Ikram

dr.muhammadikram@gcu.edu.pk

$\square$ M. Nafees

rajvi_gcu@yahoo.com

$\triangle$ J. Geng

jianxingeng@mail.ipc.ac.cn

1 Technical Institute of Physics and Chemistry, Chinese Academy of Sciences, 29 Zhongguancun East Road, Haidian District, Beijing 100190, China

2 Solar Cell Applications Research Lab, Department of Physics, Government College University Lahore, Lahore, Punjab 54000, Pakistan

3 Key Laboratory of Green Process and Engineering, Institute of Process Engineering, Chinese Academy of Sciences, Beijing 100190, China
Keywords DCB $\cdot$ EQE $\cdot$ Nanoparticles $\cdot$ BHJ $\cdot$ Active layer · Polymer

\section{Introduction}

Organic solar cells (OSCs) are attracting lot of attention as a potential replacement to Si-based photovoltaics (PV) because of being colorful, portable, easy to fabricate and cost-effective. Many recent studies report the fabrication of OSCs with promising features (Sariciftci et al. 1992; Yu et al. 1995; Günes et al. 2007; Blom et al. 2007; Dennler et al. 2009; Chen et al. 2009). Instead of p-n junctions, as in conventional Si solar cells, organic PV employ a blend of the organic and inorganic electron donor-D and acceptor-A materials, respectively, for generating charge carriers. Resulting devices consists planar heterojunctions (PHJ) where power conversion efficiency (PCE) is limited because of low exciton diffusion lengths $(<20 \mathrm{~nm}$ ) (Liang and $\mathrm{Yu}$ 2010). Excitons produced beyond the distance of more than diffusion length from the " $D$ " and " $A$ " interface will recombine and not contribute to charge generation (Park et al. 2009). Because of this reason, the power conversion efficiency (PCE) of PHJ devices is far lower than devices based on Si solar cells (Blouin et al. 2008).

With the advent of D-A bulk heterojunction (BHJ) concept, a revolutionary development occurred in PV (Ma et al. 2005). According to this concept, D and A materials are thoroughly dissolved in solvent and organized on the nanoscale to form 3-dimensional interpenetrating D/A networks that facilitate to generate charge carriers and transport in $\mathrm{BHJ}$ efficiently. By incorporation of inorganic nanostructured, the efficiency of organic BHJ devices can be enhanced to form organic-inorganic hybrid solar cells (HSC) (Li et al. 2005).

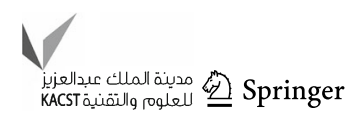


In HSC, the organic semiconductor (SC) is responsible for light harvesting acts as the hole transporter (ET) while the inorganic SC (metal oxide) can be used as an electron acceptor (EA) to improve the charge mobility (Brabec et al. 2010). The blends of organic and inorganic metal oxide can be designed by the interaction of conjugated polymer and inorganic metal oxide (Kawano et al. 2006). Devices organized from hybrids of organic and inorganic metal oxide nanoparticles have fascinated extensive importance due to their low cost relative to OSC and easy processing without the need of high vacuum by spray deposition on flexible substrates.

Up to now various electron acceptor SC oxides $\left(\mathrm{TiO}_{2}\right.$, $\mathrm{ZnO}, \mathrm{SnO}_{2}$, and $\mathrm{Nb}_{2} \mathrm{O}_{5}$ ) have been used in polymer-based active layer (Peet et al. 2007; Hauch et al. 2008; Ikram et al. 2015). These oxides exhibit high stability to photocorrosion, low toxicity, absorb the UV light and have large band gap energies (Lungenschmied et al. 2007). Although electron facilitating and injecting oxides such as $\mathrm{TiO}_{2}$, $\mathrm{ZrO}_{2}$ and $\mathrm{ZnO}$ are frequently used for improving PCE and stability of organic devices, there are other transition metal oxides like $\mathrm{NiO}, \mathrm{CuO}, \mathrm{V}_{2} \mathrm{O}_{5}$, and $\mathrm{WO}_{3}$ which are wellknown electron-injectors and facilitates hole in the active layer can be utilized for improvement in HSC device performance.

In this work, different ratios of $\mathrm{p}$ and n-type metal oxides $\left(\mathrm{NiO}\right.$ and $\left.\mathrm{TiO}_{2}\right)$-NPs was incorporated in the polymer-based active layer. The active layer of organic polymers comprises $\mathrm{P} 3 \mathrm{HT}$ and PCBM. The hybrid active layer blends were prepared in 1,2-dichlorobenzene (DCB) using various ratios of both oxides and organic polymers and found that the performances of the devices depend on the ratios in the active layer.

\section{Experimental details}

\section{Materials}

Indium-doped tin oxide (ITO) coated glass slides (25 $\Omega$ $\mathrm{sq}^{-1}$ ) were received from Lumtec-Taiwan and NiONPs $<50 \mathrm{~nm}$ from Sigma-Aldrich Co. USA. Conjugated polymer P3HT-P200 and PCBM have been purchased from (Rieke-Metals) and (SES), USA, respectively and $\mathrm{TiO}_{2}$ nanoparticles (particle size $\sim 15 \mathrm{~nm}$ ) were used in our previous study (Ikram et al. 2015).

\section{Device fabrication}

ITO slides were etched using zinc ( $\mathrm{Zn}$ ) powder and $\mathrm{HCl}$ to produce an insulated area necessary to etch the edge to prevent short-circuits. After etched, the substrates were cleaned before use by ultrasonication in a soap, distilled water, ethanol, and acetone, respectively. The cleaned substrates were immediately dried under a stream of $\mathrm{N}_{2}$ and then transferred in plasma cleaner for $10 \mathrm{~min}$. The electron transport layer (ETL) of $\mathrm{ZnO}$ was deposited using the recipe as in the literature (Lim et al. 2012). First, ZnOETL was deposited at a spinning speed $3000 \mathrm{rpm}$ for $40 \mathrm{~s}$ on plasma-cleaned ITO and annealed at $150{ }^{\circ} \mathrm{C}$ for $1 \mathrm{~h}$.

Various weight ratios of quaternary blends (P3HT:NiO:PCBM:TiO ${ }_{2}{ }^{-} \quad$ 1:0:1:0, 0.75:0.25:0.75:0.25, 0.50.0.50:0.50.0.50, and 0.25:0.75:0.25:0.75) were mixed in $1 \mathrm{ml} \mathrm{DCB}$ and stirred for $12 \mathrm{~h}$ at $40{ }^{\circ} \mathrm{C}$. The stirred solutions prior to use were passed through $0.45 \mathrm{~mm}$ polytetrafluoroethylene (PTFE) filter. The filter solutions were spin-coated on top of ETL-coated substrates and heated them at $150{ }^{\circ} \mathrm{C}$ for $15 \mathrm{~min}$ in open atmosphere. At the end, $7 \mathrm{~nm}-\mathrm{MoO}_{3}$ and $100 \mathrm{~nm}-\mathrm{Ag}$ were thermally evaporated to form a top contact on the active layer with device area of $0.2 \mathrm{~cm}^{2}$ was used for all devices. The inverted device structure of control device ITO/ZnO/(P3HT:PCBM/ $/ \mathrm{MoO}_{3} /$ $\mathrm{Ag}$ and doped were ITO/ZnO/(P3HT:NiO:PCBM:TiO ${ }_{2} /$ $\mathrm{MoO}_{3} / \mathrm{Ag}$ (Fig. 1a).

\section{Characterization}

The cells were illuminated using the solar simulator (CT 100 AAA) with a Keithley 2420 source meter under 1 sun standard irradiance $\left(100 \mathrm{~mW} / \mathrm{cm}^{2}\right.$ using as AM $\left.1.5 \mathrm{G}\right)$. The absorption spectra of the coated films were measured on a UV-visible spectrophotometer (Genesys 10S). The AFM (Ambios, Q250) was performed for active layer morphology. The external quantum efficiency was measured in air at room temperature using QEX 10-PV Measurements Inc., Boulder, CO system.

\section{Results and Discussion}

The key electrical parameters of the OPV, parasitic resistance measurement and IV-curves of binary and quaternary blend system based devices are shown in Fig. 2(a-c).

Upon mixing of $\mathrm{NiO}$ and $\mathrm{TiO}_{2}$ to the devices, it was observed better performance in the most important parameter PCE which is defined as PCE $=\frac{V_{\text {oc } * J_{\text {sc }} * F F}}{P_{\text {in }}}$, where $V_{\mathrm{oc}}$-open circuit voltage, $J_{\mathrm{sc}}$-short circuit current density, FF-fill factor and $P_{\text {in }}$ is incident light power density $\left(100 \mathrm{~mW} / \mathrm{cm}^{2}\right)$. To enhance the PCE all these essential parameters have to be increased. The $V_{\mathrm{oc}}$ in OSC devices is determined by the energy level difference between the $\mathrm{HOMO}_{\text {Donor-Highest occupied molecular orbital and the }}$ $\mathrm{LUMO}_{\text {Acceptor-lowest unoccupied molecular orbital (Chen }}$ et al. 2013; He and $\mathrm{Yu}$ 2011). $J_{\text {sc }}$ is the maximum photocurrent of the device and depends on several factors 


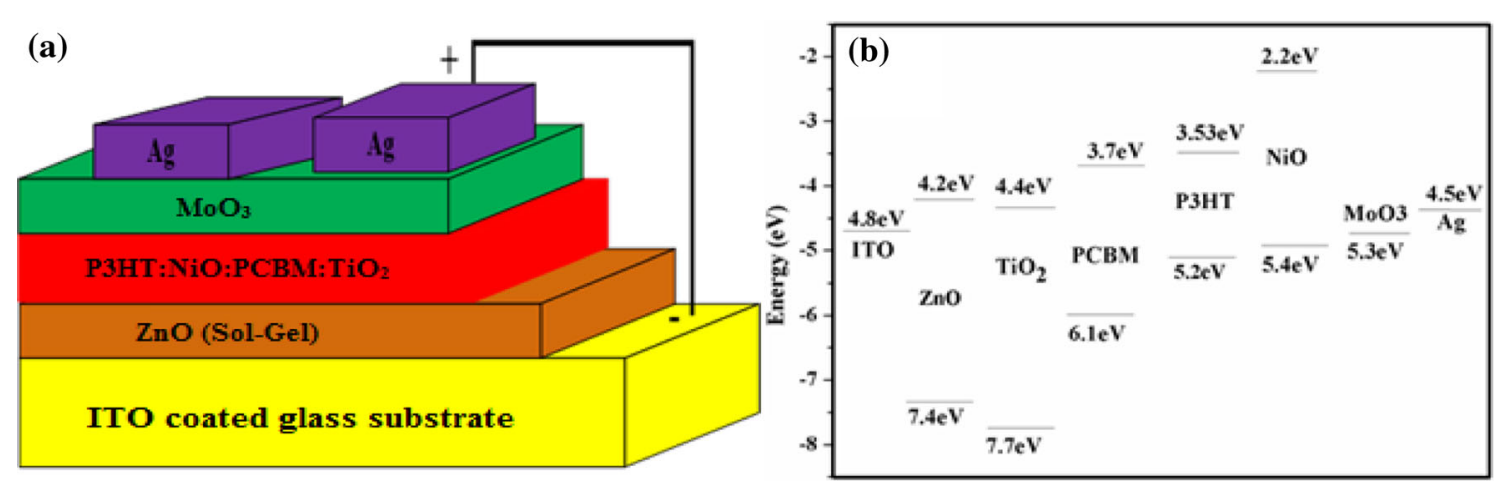

Fig. 1 Schematic representation of inverted hybrid BHJ devices (a) and energy level diagram of the materials used for preparing devices (b)
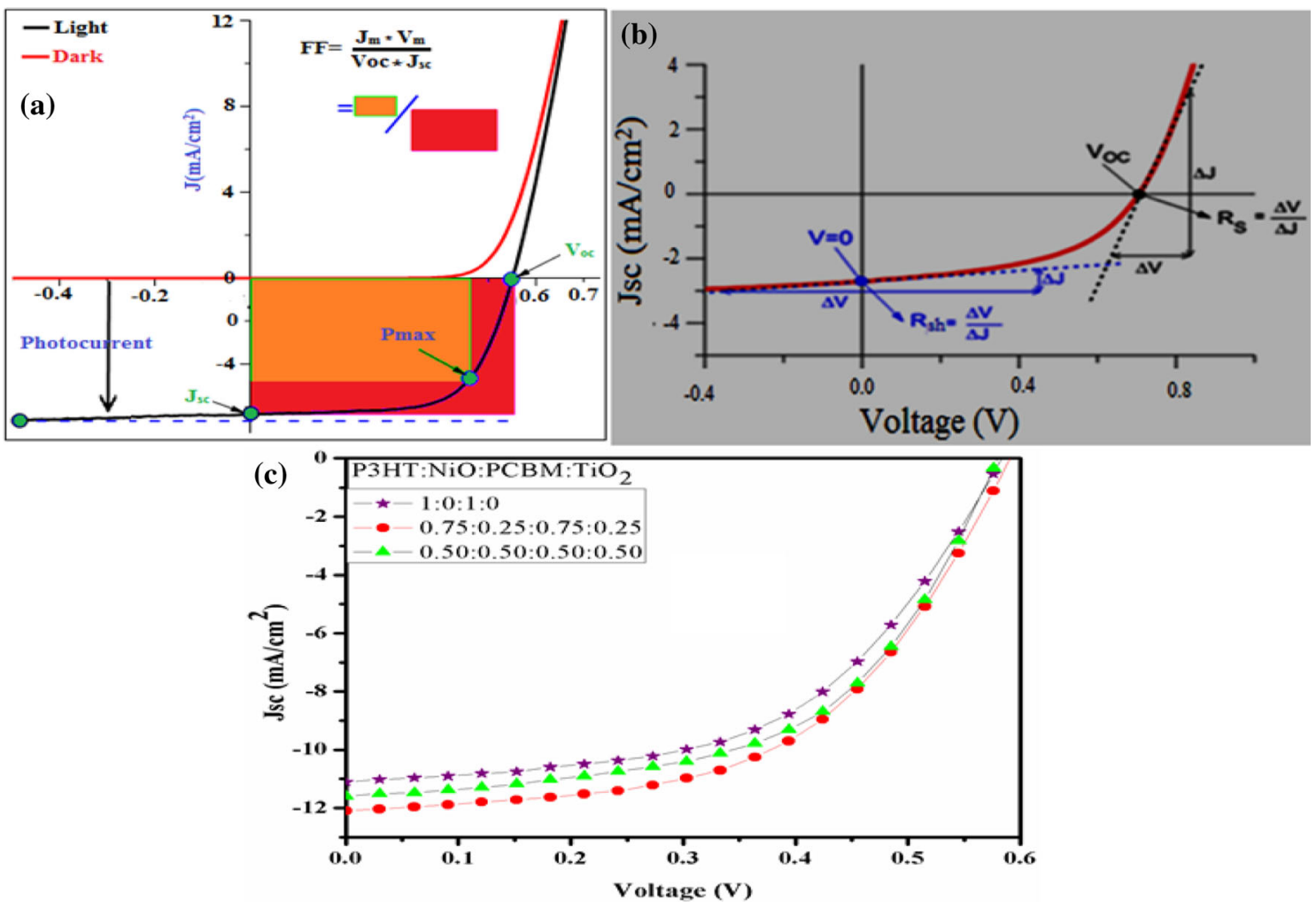

Fig. 2 Shows important parameters of solar cell (a) $R_{\mathrm{s}}$ and $R_{\mathrm{sh}}$ measurement (b) J-V characteristics of various ratios of P3HT:NiO:PCBM:TiO 2 based devices (c)

including light absorption range, surface area and thickness of photoactive layer, electron-hole generation, diffusion, separation and charge transport properties (Liang and $\mathrm{Yu}$ 2010). The FF describes the quality of the device and different phenomena that can significantly affect such as $R_{\mathrm{s}}$-series resistance, $R_{\mathrm{sh}}$-shunt resistance and competition between charge carrier recombination and transport processes (Fig. 2a). It is hard and complicated task to enhance all parameters at once (Qi and Wang 2013). $R_{\text {series }}$ is the conductivity between the films and contacts. It must be small, since it impedes the current flow. A high $R_{\mathrm{s}}$ means that electrons are struggling to flow out of the solar cell and $R_{\text {shunt }}$ is related to transport properties of SC and recombination of charge carriers at D-A interface. In this case, $R_{\text {sh }}$ is the resistance between $\mathrm{Ag}$ and ITO. It must be large, since it prevents leakage current in the backward direction. In an ideal device, $R_{\mathrm{s}}=0$ and $R_{\mathrm{sh}}=\infty$ (Yuhas and Yang 2009). The parasitic resistance $\left(R_{\mathrm{S}}\right.$ and $\left.R_{\mathrm{sh}}\right)$ can be calculated using equation of single diode model (Chenni et al. 2007)

$J=J_{\mathrm{o}}\left[\exp \left(\frac{e\left(V-J R_{\mathrm{s}}\right)}{n K_{\mathrm{B}} T}\right)-1\right]+\frac{V-J R_{\mathrm{s}}}{R_{\mathrm{sh}}}-J_{\mathrm{sc}}$

For $R_{\mathrm{s}}$, assume $R_{\mathrm{sh}}>>>1$ and algebraically solving for the voltage, 
$V=\frac{K_{\mathrm{B}} T}{q} \ln \left[\frac{J_{\mathrm{sc}}+J_{\mathrm{o}}-J}{J_{\mathrm{o}}}\right]-J R_{\mathrm{s}}$

After differentiating w.r.t "J". At open circuit between the terminals the $V=\operatorname{Voc}, J=0$ and $\frac{K_{\mathrm{B}} T}{q}<<<V_{\mathrm{oc}}$ we get,

$$
\left(\frac{\mathrm{d} V}{\mathrm{~d} J}\right)_{\text {at } V=V \mathrm{oc}}=R_{\mathrm{sh}}
$$

For $R_{\mathrm{sh}}, R_{\mathrm{s}}$ can be neglected and after differentiating w.r.t " $V$ ", At short circuit between the terminals the $V=0$ and $J=J_{\mathrm{sc}}$ which gives,

$\left(\frac{\mathrm{d} V}{\mathrm{~d} J}\right)_{\text {at } V=0}=R_{\mathrm{sh}}$

From the Fig. 2c, an increase in $\mathrm{J}_{\mathrm{sc}}$ can be observed upon introducing NPs in the active layer. A decrease in $R_{\mathrm{s}}$ results in significant increase in FF with an increasing amount of NPs in the P3HT: PCBM blend. Using the Eqs. 3 and 4, both $R_{s}$ and $R_{s h}$ were calculated by the inverse slop of $J-V$ plots at highest operating voltage $\left(V=V_{\mathrm{oc}}\right)$ and at $0 \mathrm{~V}$, respectively, as shown in Fig. $3 \mathrm{~b}$ and extracted parameter are listed in Table 1.

The increase in efficiency of the BHJ devices upon the mixing of NPs is typically manifested to decrease in series resistance as the doped devices demonstrate the higher value of $J_{\mathrm{sc}}$ versus applied voltage (V) under 1-sunlight intensity (Fig. 2c). As a result, increase in 'FF' and ' $J_{\mathrm{sc}}$ ' with increasing concentrations of both NPs in the polymerbased active layer devices can be observed. From Table 1, $R_{\mathrm{s}}$ decreased from 9.1 to $7.7 \Omega-\mathrm{cm}^{2}$ with increasing amounts of both nanoparticles. This decrease in $R_{\mathrm{s}}$ value is referred to decrease in material resistivity with the addition of metal oxide as the addition leads to additional crosslink in the network of the active layer (Lin et al. 2013). In contrast, a significant increase in $R_{\mathrm{sh}}$ from 1120 to $2490 \Omega$ $\mathrm{cm}^{2}$ because of suppression of leakage current caused by $\mathrm{p}$ and n-type NPs network (Saunders and Turner 2008; Huang et al. 2009). This decrease in resistance and a corresponding increase in device efficiency reverse with high ratios of metal oxide was attributed to large aggregations of the NPs in the P3HT:PCBM active layer, as observed in atomic force microscope (AFM) images and explained later. This severe aggregates disrupt the polymer-NPs based BHJ network and remove the pathways for electron and hole collection. The open-circuit voltage increased with the optimum amount of NPs in the P3HT and PCBM blend and dropped from BHJ network breaking down affected by large aggregations of metal oxide NPs.

From Fig. 1b shows the interfaces between (P3HT to PCBM), (P3HT to $\mathrm{TiO}_{2}$ ), (P3HT to $\left.\mathrm{NiO}\right)$, (NiO to PCBM), and $\left(\mathrm{NiO}\right.$ to $\left.\mathrm{TiO}_{2}\right)$ play an important role to increase the electron-hole separation and transport in the devices (Kettle et al. 2012; Ikram et al. 2014, 2015). The increase in photocurrent with the doping of both NPs in the P3HT and PCBM ratio leads to an increase in the C.B edge which reduces the charge recombination process due to percolation network of $\mathrm{TiO}_{2}$ NPs. The NPs-addition also has the ability to harvest light, hence, more photons were captured and more excitons were generated (Fu et al. 2012).

To check the topography of the various ratios of organic-inorganic blend surfaces, we performed AFM analyses on the films at room temperature as shown in Fig. 3a-c. Figure 3a displays the formation of the smooth surface has few small needle-like distribution of grains
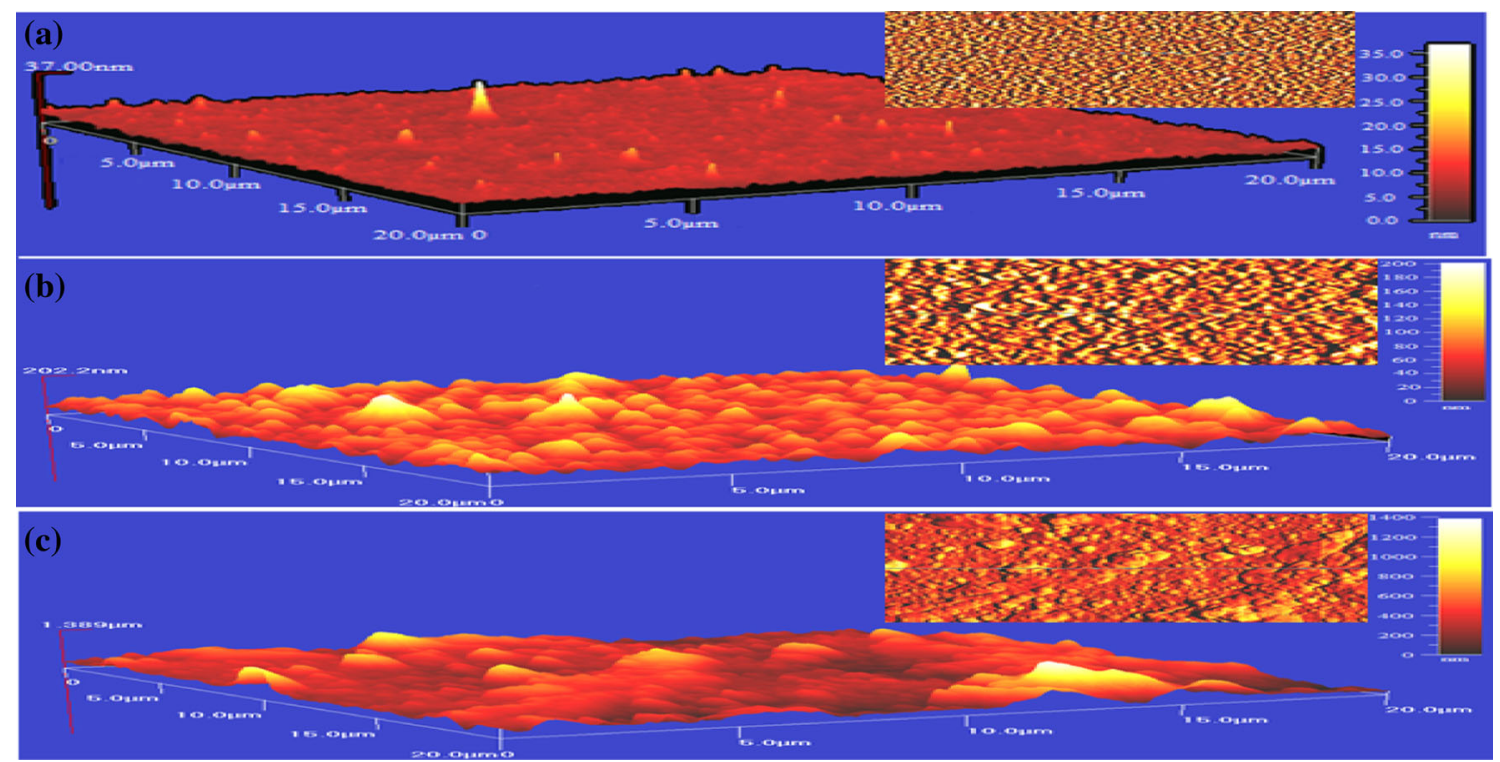

Fig. 3 AFM images (3D and 2D) with various ratios of fabricated blend films 
Table 1 Electrical parameters of various ratios of P3HT:NiO:PCBM:TiO ${ }_{2}$ obtained from Fig. 2c

\begin{tabular}{|c|c|c|c|c|c|c|}
\hline P3HT:NiO:PCBM: $\mathrm{TiO}_{2}$ & $V_{\mathrm{oc}}(V)$ & $J_{\mathrm{sc}}\left(\mathrm{mA} / \mathrm{cm}^{2}\right)$ & $\mathrm{FF}(\%)$ & $R_{\mathrm{s}}\left(\Omega-\mathrm{cm}^{2}\right)$ & $R_{\mathrm{sh}}\left(\Omega-\mathrm{cm}^{2}\right)$ & PCE $(\%)$ \\
\hline 1:0:1:0 & 0.58 & 11.1 & 53.4 & 9.1 & 1120 & 3.40 \\
\hline $0.75: 0.25: 0.75: 0.25$ & 0.58 & 11.5 & 54.83 & 6.4 & 2020 & 3.66 \\
\hline 0.50:0.50:0.50:0.50 & 0.59 & 12.2 & 53.54 & 7.7 & 2490 & 3.85 \\
\hline $0.25: 0.75: 0.25: 0.75$ & 0.47 & 8.64 & 37.12 & 33.3 & 593 & 1.51 \\
\hline
\end{tabular}

Fig. 4 Optical absorption of binary and quaternary blended layers

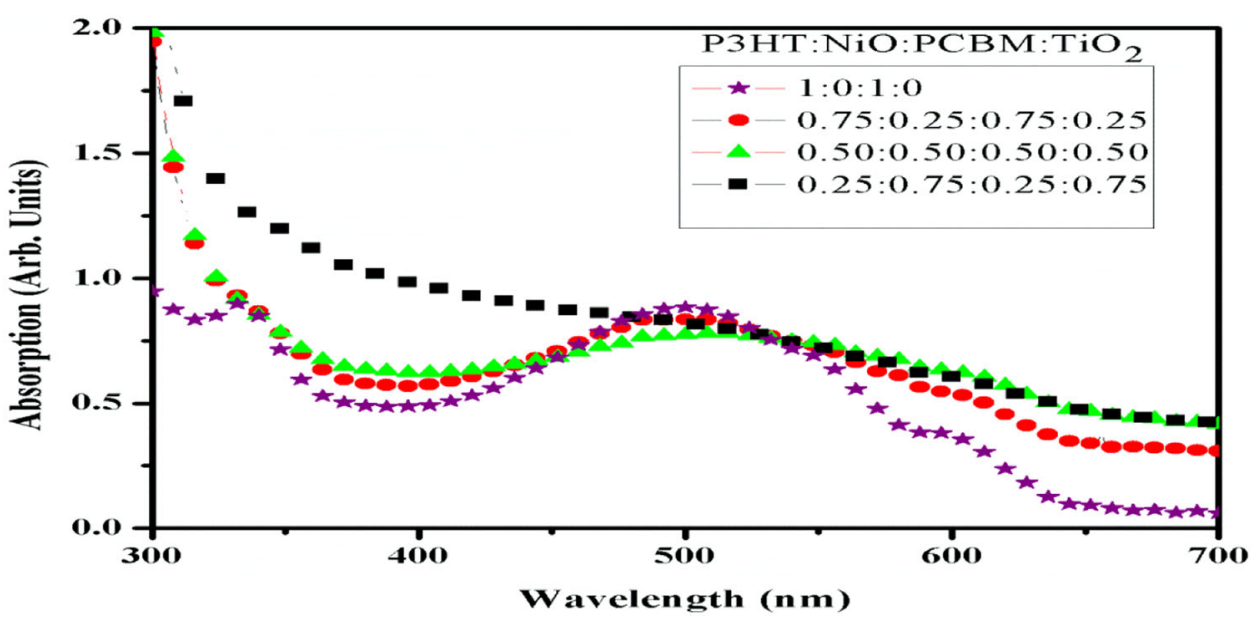

(Fig. 3a inset) with RMS roughness value is $1.7 \mathrm{~nm}$ for control active layer (1:0:1:0) free from NPs while Fig. 3bc indicate films with various ratios (0.50:0.50:0.50:0.50, 0.25:0.75:0.25:0.75) are rough to have small and large agglomerates which contribute to an RMS roughness values are $22.1 \mathrm{~nm}$ and $152.2 \mathrm{~nm}$, respectively. The deposited thin layers roughness enhanced and depends upon the increased concentration of NPs leads to aggregation of nanoparticles in the blend of P3HT and PCBM.

The absorption spectra of binary (control film) and quaternary (NPs doped) blend layers were measured in spectrum range $300-700 \mathrm{~nm}$. Figure 4 shows that optical absorption increased as the $\mathrm{NiO}$ and $\mathrm{TiO}_{2}$ amount increased in the active layer blend. As described in AFM, the surface roughness increased with increasing amount of NPs in the polymer blend. The rough surface provides longer optical path due to strong light scattering back and forth in the film which is a benefit for the light harvesting and improved IPCE (Li et al. 2007).

Figure 5 represent the measured spectra of external quantum efficiency (EQE) by focusing a monochromatic beam of light onto the various ratios of organic-inorganic based devices. It can be observed that the EQE of the devices ranged from 45 to $71.2 \%$ at $\approx 420-540 \mathrm{~nm}$ (Fig. 5) upon increasing quantity of both NPs in the blend of polymers. This increase in quantum efficiency was attributed to a broad range of absorption with the addition

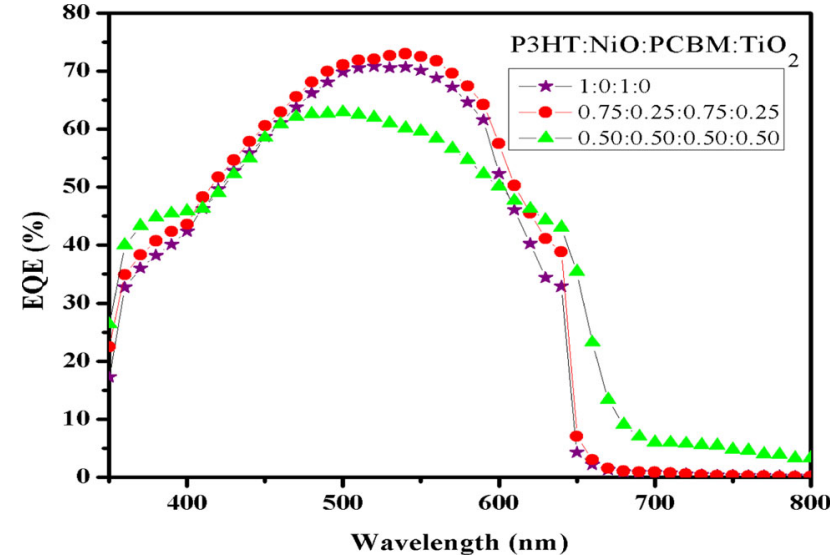

Fig. 5 External quantum efficiency curves of various ratios of the devices prepared in DCB

of NPs in the P3HT:PCBM active layer which leads to increase in electron mobility of the devices (Li et al. 2007).

Mixing of various ratios of $\mathrm{NiO}$ and $\mathrm{TiO}_{2}$ in the blend of polymers (P3HT:PCBM) bulk heterojunction with inverted architecture was studied. The incorporation of nanoparticles improved PCE from a baseline of 3.40-3.85\%. The improved PCE in doped devices can only be attributed to

\section{Conclusions}


the broad absorption range, $R_{\mathrm{sh}}$ and decrease in $R_{\mathrm{S}}$ lead to enhance charge generation and transport properties. The mixing improved the absorption and surface roughness with increasing amount of both NPs in the blend of the organic semiconductive materials. Excessive concentrations of NPs in the blend of P3HT and PCBM developed agglomerations and broke the BHJ network resulting in a degraded device performance.

Acknowledgement This work was supported by higher education commission (HEC) Pakistan. M. Imran is thankful to "CAS-TWAS President's Fellowship for International PhD Students".

Open Access This article is distributed under the terms of the Creative Commons Attribution 4.0 International License (http:// creativecommons.org/licenses/by/4.0/), which permits unrestricted use, distribution, and reproduction in any medium, provided you give appropriate credit to the original author(s) and the source, provide a link to the Creative Commons license, and indicate if changes were made.

\section{References}

Blom PWM, Mihailetchi VD, Koster LJA, Markov DE (2007) Device physics of polymer: fullerene bulk heterojunction solar cells. Adv Mater 19:1551-1566. doi:10.1002/adma.200601093

Blouin N, Michaud A, Gendron D et al (2008) Toward a rational design of poly(2,7-carbazole) derivatives for solar cells. J Am Chem Soc 130:732-742. doi:10.1021/ja0771989

Brabec CJ, Gowrisanker S, Halls JJM et al (2010) Polymer-fullerene bulk-heterojunction solar cells. Adv Mater 22:3839-3856. doi:10.1002/adma.200903697

Chen L-M, Hong Z, Li G, Yang Y (2009) Recent progress in polymer solar cells: manipulation of polymer: fullerene morphology and the formation of efficient inverted polymer solar cells. Adv Mater 21:1434-1449. doi:10.1002/adma.200802854

Chen Y, Wan X, Long G (2013) Acc Chem Res 46:2645-2655

Chenni R, Maklouf M, Kerbache T, Bouzid A (2007) A detailed modeling method for photovoltaic cells. Energy 32(9):1724-1730. doi:10.1016/j.energy.2006.12.006

Dennler G, Scharber MC, Brabec CJ (2009) Polymer-fullerene bulkheterojunction solar cells. Adv Mater 21:1323-1338. doi:10. 1002/adma.200801283

Fu H, Choi M, Luan W et al (2012) Hybrid solar cells with an inverted structure: nanodots incorporated ternary system. Solid State Electron 69:50-54. doi:10.1016/j.sse.2011.12.009

Günes S, Neugebauer H, Sariciftci NS (2007) Conjugated polymerbased organic solar cells. Chem Rev 107:1324-1338. doi:10. 1021/cr050149z

Hauch JA, Schilinsky P, Choulis SA et al (2008) Flexible organic P3HT:PCBM bulk-heterojunction modules with more than 1 year outdoor lifetime. Sol Energy Mater Sol Cells 92:727-731. doi:10.1016/j.solmat.2008.01.004

He F, Yu L (2011) J Phys. Chem. Lett. 2:3102-3113

Huang J-S, Chou C-Y, Liu M-Y et al (2009) Solution-processed vanadium oxide as an anode interlayer for inverted polymer solar cells hybridized with $\mathrm{ZnO}$ nanorods. Org Electron 10:1060-1065. doi:10.1016/j.orgel.2009.05.017
Ikram M, Murray R, Hussain A et al (2014) Hybrid organic solar cells using both $\mathrm{ZnO}$ and $\mathrm{PCBM}$ as electron acceptor materials. Mater Sci Eng, B 189:64-69. doi:10.1016/j.mseb.2014.08.005

Ikram M, Ali S, Murray R et al (2015) Influence of fullerene derivative replacement with $\mathrm{TiO}_{2}$ nanoparticles in organic bulk heterojunction solar cells. Curr Appl Phys 15:48-54. doi:10. 1016/j.cap.2014.10.026

Kawano K, Pacios R, Poplavskyy D et al (2006) Degradation of organic solar cells due to air exposure. Sol Energy Mater Sol Cells 90:3520-3530. doi:10.1016/j.solmat.2006.06.041

Kettle J, Waters H, Horie M, Chang S-W (2012) Effect of hole transporting layers on the performance of PCPDTBT: PCBM organic solar cells. J Phys D Appl Phys 45:125102. doi:10.1088/ $0022-3727 / 45 / 12 / 125102$

Li G, Shrotriya V, Huang J et al (2005) High-efficiency solution processable polymer photovoltaic cells by self-organization of polymer blends. Nat Mater 4:864-868. doi:10.1038/nmat1500

Li G, Shrotriya V, Yao Y et al (2007) Manipulating regioregular poly(3-hexylthiophene): [6,6]-phenyl- $\mathrm{C}_{61}$-butyric acid methyl ester blends-route towards high efficiency polymer solar cells. J Mater Chem 17:3126. doi:10.1039/b703075b

Liang Y, Yu L (2010) A new class of semiconducting polymers for bulk heterojunction solar cells with exceptionally high performance. Acc Chem Res 43:1227-1236. doi:10.1021/ar1000296

Lim Y-F, Choi JJ, Hanrath T (2012) Facile synthesis of colloidal CuO nanocrystals for light-harvesting applications. J Nanomater 2012:1-6. doi:10.1155/2012/393160

Lin J-F, Tu G-Y, Ho C-C et al (2013) Molecular structure effect of pyridine-based surface ligand on the performance of $\mathrm{P} 3 \mathrm{HT}: \mathrm{TiO}_{2}$ hybrid solar cell. ACS Appl Mater Interfaces 5:1009-1016. doi:10.1021/am302700c

Lungenschmied C, Dennler G, Neugebauer H et al (2007) Flexible, long-lived, large-area, organic solar cells. Sol Energy Mater Sol Cells 91:379-384. doi:10.1016/j.solmat.2006.10.013

Ma W, Yang C, Gong X et al (2005) Thermally stable, efficient polymer solar cells with nanoscale control of the interpenetrating network morphology. Adv Funct Mater 15:1617-1622. doi:10. 1002/adfm.200500211

Park SH, Roy A, Beaupré S et al (2009) Bulk heterojunction solar cells with internal quantum efficiency approaching $100 \%$. Nat Photonics 3:297-302. doi:10.1038/nphoton.2009.69

Peet J, Kim JY, Coates NE et al (2007) Efficiency enhancement in low-bandgap polymer solar cells by processing with alkane dithiols. Nat Mater 6:497-500. doi:10.1038/nmat1928

Qi B, Wang J (2013) Phys Chem Chem Phys 15:8972-8982

Sariciftci NS, Smilowitz L, Heeger AJ, Wudl F (1992) Photoinduced electron transfer from a conducting polymer to buckminsterfullerene. Science 258:1474-1476. doi:10.1126/science.258. 5087.1474

Saunders BR, Turner ML (2008) Nanoparticle-polymer photovoltaic cells. Adv Colloid Interface Sci 138:1-23. doi:10.1016/j.cis. 2007.09.001

Yu G, Gao J, Hummelen JC et al (1995) Polymer photovoltaic cells: enhanced efficiencies via a network of internal donor-acceptor heterojunctions. Science 270:1789-1791. doi:10.1126/science. 270.5243.1789

Yuhas BD, Yang P (2009) Nanowire-based all-oxide solar cells. J Am Chem Soc 131:3756-3761. doi:10.1021/ja8095575

\section{Publisher's Note}

Springer Nature remains neutral with regard to jurisdictional claims in published maps and institutional affiliations. 